\title{
IMPROVEMENTS ON THE ELECTRIC DRIVE ELEVATOR PROTOTYPE. PART I TECHNICAL ASPECTS
}

\author{
M. GAICEANU ${ }^{1}$, S. EPURE ${ }^{1}$ \\ ${ }^{1}$ Dunarea de Jos University of Galati-Romania \\ E-mail: Marian.Gaiceanu@ugal.ro
}

\begin{abstract}
The objective of the paper is to present some improvements done on the previously described electric drive elevator prototype [1]. The modern electric elevator contains both the cabin (replaced at the research laboratory by one trolley), and the counterweight (replaced by the opposite trolley which contains modular weights). Through the appropriate gearbox the connexion between the pulley and electric motors is provided. The designed load of the elevator conducts to the $4 \mathrm{~kW}$ three-phase squirrel cage driven motor supplied by the power inverter prototype through the chain transmission. The modified experimental platform is depicted and the adequate experimental results are provided.
\end{abstract}

Keywords: electric lift, squirrel cage, regenerative power converter

\section{INTRODUCTION}

Following a further analysis of the sales of elevator products, a range of powers have been identified in which prototype production could enter on the market. Several manufacturers of elevators have been identified both in Romania and abroad. From Romania, the following enterprises can be mentioned: SC ASCENSO SRL - Cluj Napoca [2]; DIAMOND LIFT COM. LLC - Bucharest [3], Elmas SRL - Braşov [4], MP IFMA - Bucharest [5], S.C. ASEL S.A. - Targoviste [6], ASCENSORUL S.A. Bucharest [7], OTIS Lift SRL -Bucureşti [8], Kleemann LiftRO - Bucharest [9].

From abroad, the following elevators manufactures can be mentioned: Schindler Group - Switzerland, Stannah Lifts Holdings Ltd - England [10], Thyssenkrupp - Germany [11], Toshiba Elevator and Building Systems Corporation - Japan [12], Hiro Lift - Germany [13], ORONA -Spain, Cibes Lift - Gävle, Sweden [14], Hitachi - Chiyoda, Tokyo [15], Hyundai Elevator - Korea [16], KONE Oyj Helsinki, Finland [17]; Marchall Elevator - USA [18], Mitsubishi Electric - Japan [19]. In this study, for each manufactures, we present the following characteristics: the maximum vertical distance, the load, the number of stations, the speed of travel, and the type of the traction.

\section{THE ENERGY CONVERSION}

Research activities have been carried out to improve the existing electric drive elevator (EDE) performances: the 16 bits digital signal processor is included on the control board of the power inverter prototype; the dc link voltage is increased over the $600 \mathrm{~V}$ level, and the pre-charge power circuit has been improved limiting the load current to $10 \mathrm{~A}$. As an additional safety measure a brake circuit has been designed and implemented. Power modules have been ordered with voltages of up to $1200 \mathrm{Vcc}$ and currents of $450 \mathrm{~A}$, controlled by the dSpace platform. Another direction of improvement was the control implementation of the power inverter/converter based on the FPGA technology. The prototype of the elevator is shown in Figure 1 [1]. At the same time a large analysis of the manufactures of the elevators has been done [1].

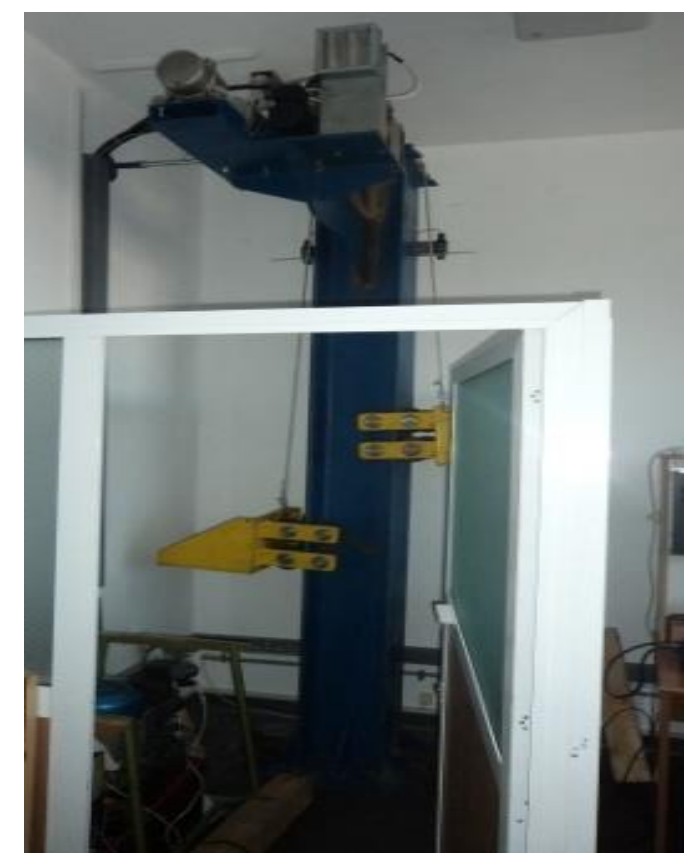

Figure 1. The prototype of the electric driven elevator [1]

In the Figure 2 the dynamic sizing of the electromechanical power converter is shown. It consists of the imposed speed profile. Based on the adequate coupling design, the linear speed is transferred to angular one $\left(v_{\text {ref }}-\right.$ reference speed). Based on the adequate speed regulator the electromagnetic torque is obtained. By reducing the elevator load to the electric motor, the fundamental circular motion equation, available for the direct load coupling to the electric motor, can be applied (Figure 2). 


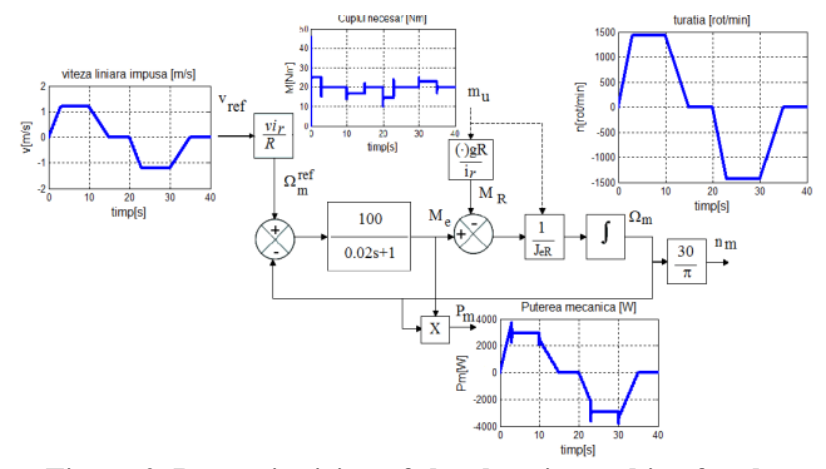

Figure 2. Dynamic sizing of the electric machine for the elevator starting from the imposed speed profile

Functional tests have been performed on all system components with different loads. In order to use a high dc link voltage level a precharge circuit is mandatory.

Within the research activities, a new precharge circuit has been proposed and tested. At the same time, numerical and analogue interfaces have been designed and implemented. The grid power converter has been tested based on the original developed control.

\section{THE TECHNICAL ASPECTS FOR THE ELECTRIC DRIVE ELEVATOR}

This Section is designed to highlight the technical aspects of the Integrated Regenerative Power System prototype in order go forward with the prototype on to the design and development of a family of static power converters. Moreover, this Section highlights the potential beneficiaries/ users or product integrators. The technical specifications are the result of a feasibility study, a study that includes the following steps:

- the study of technical literature and research papers in the field, published in journals and specialized conferences;

- simulation of various technical solutions;

- study of the market.

These three main pilings have led to the performances definition and to choose the appropriate components of the prototype: power structure; control structure; desired performances; defining the mechanical structure; program development tools (for example, compilers and appropriate programming software). It also took into account the minimization of electromagnetic emissions.

Specifications are based on specific standards, divided into the following categories:

a) general standards: EN 61800-2, IEC 146-1-1;

b) protection: EN 50178, UL 508C;

c) distance and limit exceed: EN 50178, UL 508C, UL 840

d) climate: EN 60721-3-3, dielectric breakdown immunity: 4kV / 2kV according to EN 61000-4-4

e) immunity to accidental overload: $1 \mathrm{kV} / 2 \mathrm{kV}$ according to EN 61000-4-5, f) conducted emissions: limit "A" in EN 55011 with filters; line current harmonics: EN 60555-2, EN 60555-3, EN 61000-3-2, EN 61000-3-3, EN 61000-34, EN 61000-3-5;

g) rated input voltages: IEC 60038;

h) degree of protection IP20 according to EN 60529.

i) Permissible environmental conditions: ambient temperature: $0 \ldots+40^{\circ} \mathrm{C} ; 0 \ldots+50^{\circ} \mathrm{C}$ with derating;

j) installation place: Pollution degree 2 or better; installation altitude: up to $1000 \mathrm{~m}$ above sea level; for higher altitudes, a $1.2 \%$ output reduction should be applied every $100 \mathrm{~m}$ of additional height, operating temperature $0 \ldots+40^{\circ} \mathrm{C} / 0 \ldots+50^{\circ} \mathrm{C}$ with corrections $\left(\mathrm{kV}=0.87 \mathrm{kT}=0.8 @ \mathrm{TA}=+50{ }^{\circ} \mathrm{C}\right)$;

k) storage temperature: $25 \ldots+55^{\circ} \mathrm{C}$ according to $\mathrm{EN}$ 50178 Class $1 \mathrm{~K} 4$;

1) transport temperature $-25 \ldots+70^{\circ} \mathrm{C}$, class $2 \mathrm{~K} 3$ according to EN 50178;

m) air pressure: operating 86 to $106 \mathrm{kPa}$, class $3 \mathrm{~K} 3$ according to EN 50178;

n) storage pressure 86 to $106 \mathrm{kPa}$, class $1 \mathrm{~K} 4$ according to EN 50178;

o) air pressure at transport 70 to $106 \mathrm{kPa}$, class $2 \mathrm{~K} 3$ according to EN 50178.

Taking into account all the above mentioned restrictions and guidance the following main technical specifications are derived:

1. Power supply converter (based on the three-phase IGBT bridge): $\mathrm{ULN}=380 \mathrm{~V}$, THD line current $\mathrm{ILN} \leq 5 \%$, modulation type: sine wave, optimized, 3rd order harmonic insertion, space vector modulation; The default switching frequency: $8 \mathrm{kHz}, \cos \varphi \mathrm{L} 1=1$ (motor) $=1$ (generator) / (is fixed by the control); Rated dc link current IdN (@ $\left.\mathrm{U}_{\mathrm{LN}}=230 \mathrm{Vac} / 400 \mathrm{Vac}, \mathrm{cl} .1\right)=34 \mathrm{Acc}$, The rated dc link voltage $\mathrm{U}_{\mathrm{dN}}\left(@ \mathrm{U}_{\mathrm{LN}}=400 \mathrm{Vac}\right)=690 \mathrm{Vcc}$, circuit Overvoltage Limit $=820 \mathrm{Vcc}$, Lower dc link Voltage Limit $\left(@ \mathrm{U}_{\mathrm{LN}}=230 \mathrm{Vac}\right)=360 \mathrm{~V}$, bandwidth of the voltage regulator $\geq 200 \mathrm{rad} / \mathrm{sec}$, bandwidth of the current regulator $\geq 1000 \mathrm{rad} / \mathrm{sec}, \quad \mathrm{C}=1565 \mathrm{uF}$, Lin $=2.64 \mathrm{mH}, 5 \% /+10 \%, \mathrm{P}=22 \mathrm{~kW}$.

2. Motor 1 to Output Power Converter (from Figure1) $\mathrm{PN}_{\mathrm{N}}$ mot. (@ 400Vac, cl. 1, fsw =default): 4kW, I I cl. 1 (@ 400Vac, $\mathrm{fsw}_{\mathrm{s}}=$ default $)=\mathrm{A}$, Modulation type $=$ space vector modulation, default switching frequency $\mathrm{f}_{\mathrm{sw}}=4 \mathrm{kHz}$, $(\mathrm{dV} / \mathrm{dt}) \max =4 \mathrm{kV} / \mathrm{us}, \mathrm{Max} . \mathrm{U}_{2}=0,612 \mathrm{U}_{\mathrm{dN}}$, Max. $\mathrm{f}_{2}=400 \mathrm{~Hz}$; 3. Three-phase inductance specifications for $22 \mathrm{~kW}$ prototype: nominal value: working voltage: 3 x $400+$ $10 \%$, working frequency (fundamental): $45-65 \mathrm{~Hz}$, insulation voltage: $3000 \mathrm{Vef}-60 \mathrm{~s}$, insulation class: F, H, rms rated current $400 \mathrm{~V} / 50 \mathrm{~Hz}$ : $34 \mathrm{Arms}$, overload current 400V/50Hz:47Arms, overload time: 60s every 300s, Saturation current $\left(\mathrm{L}_{\mathrm{sat}}=80 \% \mathrm{~L}_{\text {nom }}\right)$ : $105 \mathrm{Apk}$;

4. EMI filter - required to meet the "B" limit of EN 55011 for elevators;

5. Pre-charging circuit: It is done by connecting three resistors in series on the power input side. When the precharging voltage is reached, the resistors are shortcircuited by a contactor. The contactor must be opened again in the event of a sub-tension, to allow for a new 
operating cycle so that line voltages and continuous (intermediate) voltages go back to nominal values. The contactor closure / opening is monitored by reading an NC auxiliary contact;

6. Current and voltage transducers - In order to calibrate the control circuits, the characteristics of the transducers have been determined experimentally.

The design and building of the prototype took into account the general and specific health and safety rules for the elevator equipment. A special place has been set-up in the research lab, the access being restricted by enclosing the area with double-glazed walls and an access door (Figure1). Also, given that it is an elevator device and complies with ISCIR standards, the electric drive motor is equipped with a brake. Last but not least, the setting of an overload safety factor for overloads in the parameterization of frequency power converter for the operation of the electric motor has been done.

\section{PRECHARGE AND BRAKING CIRCUITS}

The main challenge of the pre-charge circuit has been the increase of the voltage operation in the dc-link (1200V).

The first version of the pre-charge circuit uses a timing circuit for controlling two electromagnetic relays, which short-circuit the series resistor by which the dc voltage capacitor of the intermediate circuit is pre-charged. Under certain conditions, when the relay is switched, the maximum current through the relay contacts reaches values far above those permitted by the manufacturer (about two times more to the rated current 10A), which can lead to welding of contacts and faulty circuit operation. In addition, the fixed timing does not give circuit flexibility, and the non-synchronization between the timer constant and the RC group time constant $(\mathrm{R}=$ pre-charge resistor, $\mathrm{C}=\mathrm{dc}$ link capacitor) can lead to unwanted effects. The redesigning activity highlights the new pre-charge circuit as well as a braking circuit for overvoltage protection of the power hardware (Figure 3 ).

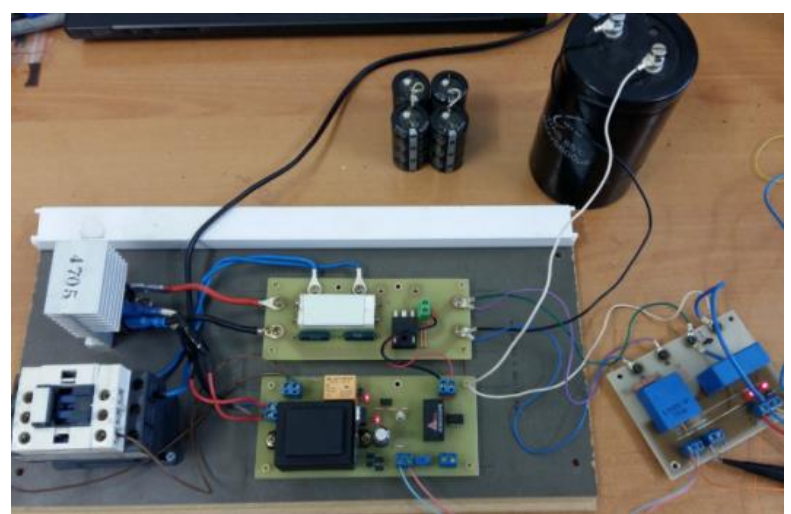

Figure 3. Pre-charge and braking circuit

The operation of a $5600 \mathrm{uF} / 400 \mathrm{~V}$ capacitor powered from the $230 \mathrm{Vac}$ single-phase grid has been tested using only two of three-phase bridge rectifier arms. The switching voltage threshold has been set so that the capacitor is charged almost at the peak voltage of the mains voltage when the dc link supply contactor is switched such that the pre-charge resistors are short circuited. The delay between power supply and contactor control is approx. $3 \mathrm{~s}$, during which charging current is limited by a resistance of $33 \Omega$. The waveforms for the voltage at capacitor terminals and capacitor current are shown in the following figure (Figure 4).

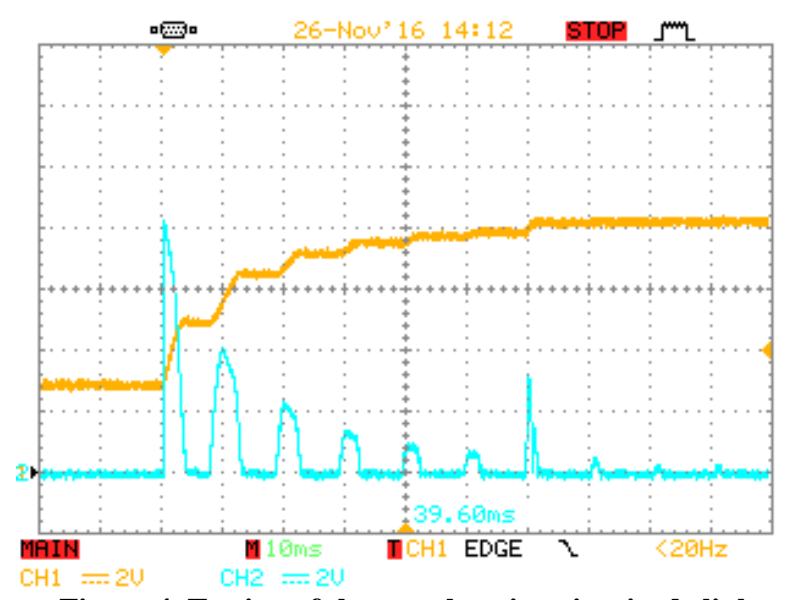

Figure 4. Testing of the pre-charging circuit: dc link current (green) and dc link pre-charging voltage (yellow)

The used voltage transducer constant and of the current transducer are $0.025 \mathrm{~V} / \mathrm{V}$ (38.8V / oscilloscope division), and $0.33 \mathrm{~V} / \mathrm{A}$ (1.33A / division) respectively. The value of the first peak corresponds to the first positive alternance and it is given by the peak voltage of the grid and the series resistance value:

$$
\hat{I}=\frac{\hat{U}}{R},
$$

or numerically:

$$
\hat{I}=\frac{220 \sqrt{2}}{33}=9,44 A
$$

by assuming that the initial voltage at the capacitor terminals was null.

\section{PROTOTYPE OF THE THREE-PHASE POWER INVERTER}

At present, there are a multitude of monolithic integrated circuits that can control both the transistor of a bridge, up to $600 \mathrm{~V}$ continuous supply voltage. In order to use the module in applications with dc link voltage higher than $600 \mathrm{~V}$, special gate control circuits are required [20, 21], but they do not exist in integrated form. It has been chosen to use an isolated voltage source for each floating transistor and to control it with an integrated circuit specialized in the control of the non-floating transistors. Isolation of control signal is done with high-speed digital optocouplers, so that dead time requirements do not increase significantly. 


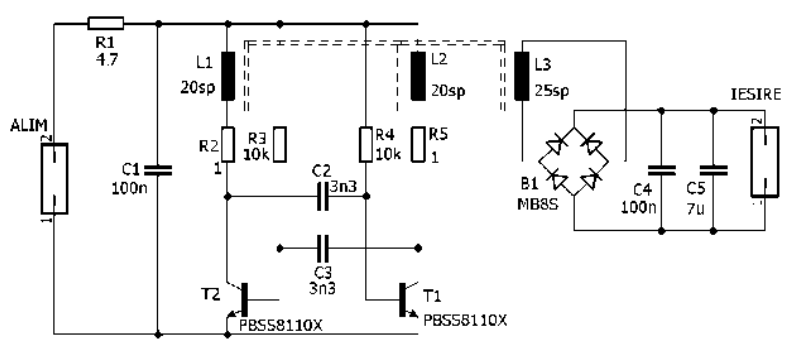

Figure 5. Isolated voltage source scheme

Figure 5 shows the schematic and practical embodiment of the isolated voltage source. The insulation barrier capable of supporting $1200 \mathrm{~V}$ is obtained by distancing the input and output circuits by coiling the transformer with an insulated conductor that supports $1200 \mathrm{~V}$ and by covering the circuit with the protective lacquer. All components are located on one side of the harness so that the source can be used in the final assembly superimposed over the galvanic insulating floor and the IGBT driver.

Figure 6 shows the projected printed wiring harness and the practical realization of the source. The circuit is a selflocking oscillator with an oscillation frequency of 40 to $100 \mathrm{kHz}$, depending on the supply voltage and output in the output circuit. Due to the location of the coils as in the figure above, the operation is a push-pull stage. Resistors R1, R2 and R5 stabilize the operating point and protect the transistors in the event of a short-circuit at the output. The rectangular voltage and no notable overvoltages in the transformer's secondary is rectified and filtered, resulting in continuous output voltage.
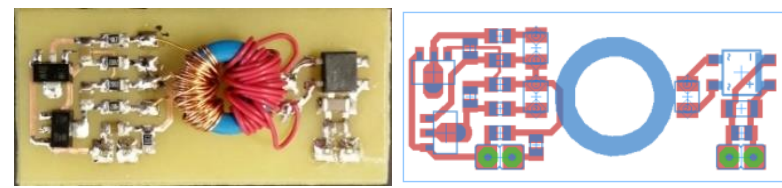

Figure 6. Practical realization of the isolated voltage source

Figure 7 shows the voltage in the collector of a transistor (the brown signal) along with the continuous output voltage (the blue signal). It is noted that the output voltage has a value of approx. $14 \mathrm{~V}$, without periodic variations caused by oscillator switching. Typically the push-pull circuit, the voltage in the transistor collector varies between 0 and double of the supply voltage.

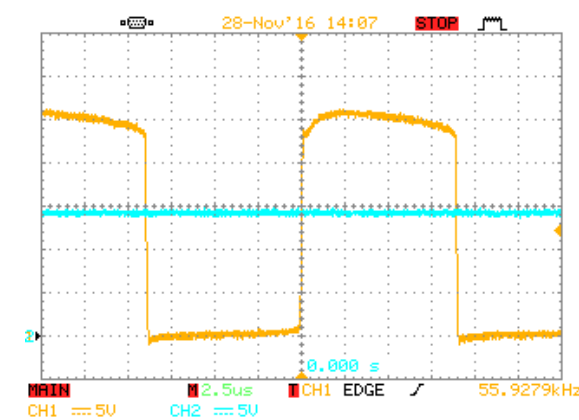

Figure7. Testing of the isolated voltage source

For the PWM inverter the circuit shown in Figure 8 has been provided. An integrated IGBT module has been used. The appropriate six (6) galvanic isolated drivers have been designed and built to allow the module to be energized at any continuous voltage between $15 \mathrm{~V}$ and 1000V (Figure 8).

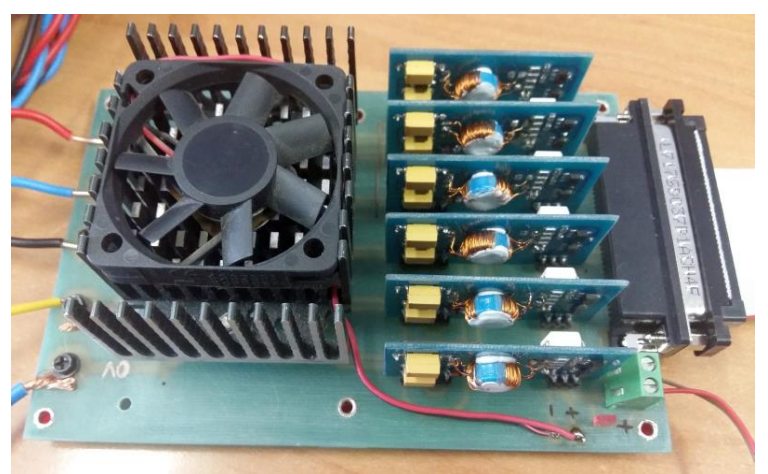

Figure. 8. The prototype of the three-phase power inverter

The circuit does not add the dead time to the transistor control; therefore, it is necessary to set this parameter directly from the PWM control module for the power inverter. Each of the 6 drivers is based on the dedicated integrated circuit that implements the control of an IGBT transistor: adjustable current for charging and discharging the grid-emitter capacity; keeping of the grid at negative potential during transistor blocking; short circuit of the grid (very low impedance) to the negative voltage supply during the blocking of the transistor ("active Miller clamp") in order to avoid the conduction entry of the transistor due to the fast increase and high amplitude of the voltage in the transistor collector; decreasing of the command voltage on the gate before passing the transistor in the blocked state in order to reduce the switching overvoltages (two-level turn off - TLTO); transistor desaturation protection that make the transition of the transistor state in the blocked state if the collector-emitter voltage exceeds a predefined value during the conduction (providing short-circuit protection of the transistor); signalling malfunction of the power transistor; protection to under-voltage.

\section{CONCLUSIONS}

In this paper, the authors underlined the technical specifications of the electric elevator. In order to enter on the market, one necessary improvement consists of the increasing of the dc link voltage. As a consequence, in order to pilotate the IGBT power transistor, the isolated drive circuit is necessary. An original isolated voltage source has been designed and delivered by the authors.

\section{ACKNOWLEDGMENTS}

This work was supported by a grant of the Romanian National Authority for Scientific Research, CNDIUEFISCDI, project number PN-II-PT-PCCA-2011-3.21680. 


\section{REFERENCES}

[1] M. Gaiceanu, S. Epure, C. R. Dache, S. Ciuta, Prototype of an Electric Drive Elevator, doi.org/10.1515/sbeef-2016-0024

https://www.degruyter.com/view/j/sbeef.ahead-ofprint/sbeef-2016-0024/sbeef-2016-0024.xml

[2] www.ascenso.ro

[3] http://www.bucuresticonstruct.ro/diamond-lift-cominstalatii-de-ridicat-lifturi-platforme-auto-si-pentrumarfa-scari-si-trotuare-rulante.html

[4] Instalatii de ridicat, Ascensoare, Macarale industriale - Elmas, www.elmas.ro/produse.php

[5] www.mpifma.ro/

[6] www.ascensorul.ro

[7] asel-ascensoare.ro/

[8] www.otisworldwide.com/site/ro/pas/ ContactOtis.aspx

[9] www.kleemannlifts.ro/?lang=ro

[10] https://www.schindler.com/

[11] https://www.thyssenkrupp.com/en

[12] www.toshiba-elevator.co.jp/elv/infoeng/

[13] www.hirolift.com/

[14] se.cibeslift.com/

[15] www.hitachi-elevator.co.th/pdf/Hitachi-Lift-OVF.pdf

[16] www.hyundaielevator.co.kr/eng/

[17] www.kone.com/en/

[18] www.marchalstevensonelev.com/

[19] www.mitsubishi.com

[20] http://www.analog.com/en/technical-articles/igbtovercurrent-and-short-circuit-protection-inindustrial-motor-drives.html

[21] http://www.analog.com/media/en/technicaldocumentation/application-notes/AN-1265.pdf 